\title{
Editorial: Macrophages Role in Integrating Tissue Signals and Biological Processes in Chronic Inflammation and Fibrosis
}

\author{
Tarcio Teodoro Braga ${ }^{1 *}$, Ivan C. Moura ${ }^{2}$, Ana Paula Lepique ${ }^{1}$ and \\ Niels Olsen Saraiva Camara ${ }^{1,3,4}$ \\ ${ }^{1}$ Immunology Department, University of São Paulo, São Paulo, Brazil, ${ }^{2}$ Institut national de la santé et de la recherche \\ médicale (INSERM), Paris, France, ${ }^{3}$ Nephrology Division, Medicine Department, Federal University of São Paulo, São Paulo, \\ Brazil, ${ }^{4}$ Renal Physiology Laboratory, Faculty of Medicine, University of São Paulo, São Paulo, Brazil
}

Keywords: chronic inflammation, fibrosis, macrophage plasticity, macrophage subtypes, homeostasis maintenance

\section{Editorial on the Research Topic}

Macrophages Role in Integrating Tissue Signals and Biological Processes in Chronic Inflammation and Fibrosis

\section{OPEN ACCESS}

Edited and Reviewed by: Francesca Granucci, University of Milano-Bicocca, Italy

${ }^{*}$ Correspondence: Tarcio Teodoro Braga tarcio_tb@yahoo.com.br

Specialty section:

This article was submitted to Molecular Innate Immunity, a section of the journal Frontiers in Immunology

Received: 12 June 2017 Accepted: 05 July 2017 Published: 21 July 2017

Citation:

Braga TT, Moura IC, Lepique AP and Camara NOS (2017) Editorial: Macrophages Role in Integrating

Tissue Signals and Biological Processes in Chronic Inflammation and Fibrosis.

Front. Immunol. 8:845. doi: 10.3389/fimmu.2017.00845
Macrophages comprehend a population with wide range phenotypes and roles in homeostasis maintenance and diseases. Technology improvements enable researchers to track different macrophage populations in different tissues and situations and hypothesize on their role in promoting inflammation or maintaining tissue homeostasis. In the present editorial, we present a concise series of discussions on the role of these cells, its response to the microenvironment, and effects on other cells during tissue injury and repair. We also discuss the themes proposed by the authors on macrophage plasticity during fibrotic processes in the context of the topic subject. M1 macrophages are considered foe cells for the pro-fibrotic process once they are associated with pro-inflammatory functions (Braga et al.), and an exacerbation of tissue inflammation initiates the pro-fibrotic process (1). On the other hand, M2 macrophages have anti-inflammatory properties due to its ability to secrete IL-10, arginase, and TGF- $\beta$ (2). However, when the insult is persistent, excessive M2 macrophage activation leads to continuous TGF- $\beta$ production, promoting increased extracellular matrix deposition (3). In this scenario, despite its friendly behavior against the exacerbated fibrosis development, M2 becomes foe cells in the tissue repairing. Macrophages are also able to influence innate lymphoid cells (ILCs) during the fibrotic process (Hams et al.). Repetitive cycles of epithelial damage and repair are able to generate fibrosis through the release DAMPs and alarmins by epithelium (4). Among the alarmins, IL25, IL33, and TSLP are able to polarize ILCs to the ILC2 phenotype. ILC2 can enhance Th2 responses and collagen deposition (5, 6), either indirectly via IL13-mediated dendritic cell priming or directly through CD4-T cells interaction (via MHCII-CD4) $(7,8)$. In addition, ILC2 produces IL4 and IL5 and induces tissue collagen deposition in pulmonary and hepatic models of fibrotic diseases $(9,10)$. In turn, deficiency of IL25 and IL33 or their receptors, IL17RB and ST2, respectively, leads to decreased collagen deposition $(5,9)$. However, the apparent redundancy of these alarmins may be due to different ligand and receptor expression at different anatomical sites (11).

ILC2s interact with macrophages on the improvement of obesity-induced insulin resistance (Castoldi et al.). Different subtypes of macrophages are related to the maintenance of adipose tissue (AT) homeostasis during the lean state, obesity, and insulin resistance (Castoldi et al.). It has been known that the microenvironment in a lean AT is composed of macrophages subtypes in a ratio of 
4:1 M2:M1 (12). To maintain AT homeostasis in this lipid-rich microenvironment, macrophages present increased adiposity (13) and increased expression of fatty acids transporters (13). However, obesity status triggers the accumulation of M1 macrophages, although it was reported that the secretion of pro-inflammatory cytokines in AT is dependent on peroxisome proliferator-activated receptor gamma (PPAR- $\gamma$ ), an M2 marker (14). Inflammatory factors present in obesity context lead to insulin resistance, characterized by decreased phosphorylation of insulin receptor substrate-1 and -2 , decreased phosphorylation of Akt $(15,16)$ and activation of the mammalian target of rapamycin signaling pathway (17), a sensor of nutrients able to alter the cellular metabolism. In obesity, nutrient sensing by mTOR regulates the switch of ATMs from M2 to M1 (18). However, obesity can be controlled through the production of large amounts of anti-inflammatory cytokines and the induction of uncoupling protein 1 expression in AT, a process called "beiging" or "browning" (19). In line with the relationship between AT and inflammation, it has been reported high levels of inflammatory mediators in the context of cachexia (de MatosNeto et al.), a health problem present especially in cancer patients (20). Weight loss, the most visible feature of cachexia, is accompanied by increased production of CCL2, CCL3, TNF $\alpha$, and IL1 $\beta$ and reduced relative numbers of M2 macrophages in the tumor environment (de Matos-Neto et al.).

Macrophages directly influence the metabolic status of the organism (21). Different sterile inflammation, in special type 1 diabetes (T1D) can be triggered by leukotriene B4 (LTB4) (Filgueiras et al.). Filgueiras et al. wonder if LTB4 could be targeted in new therapy strategies for treating T1D once LTB4 could either increase pro-IL1 $\beta$ expression or potentiate the IL1R activation by modulating MYD88. Previously, the same group has demonstrated that low insulin concentrations are able to induce LTB4 production, which triggers systemic inflammation through MyD88 and its transcriptional effector STAT-1 (signal transducer and activator of transcription 1) (22). On the other hand, insulin-treated mice showed less LTB4 in the blood and reduced Myd88 and Stat 1 expression in macrophages. In addition, diabetic mice lacking 5-lipoxygenase or the receptor for LTB4 produced less pro-inflammatory cytokines (22). Mitochondrial DNA (mDNA) derived from diabetic mice is also implicated in the activation of NLRP3 and IL1 $\beta$ in the context of T1D (Carlos et al.). It has been known that NLRP3 deficiency plays a protective role against T1D (23) and that polymorphisms in NLRP3 are associated with T1D (24), however, the precise mechanisms by which NLRP3 is triggered in the context of T1D was poorly explored. Besides demonstrating the importance of NLRP3 for the development of T1D, Carlos et al. also took advantage of a sub dosage model of disease that is not able to induce T1D, unless mDNA was given concomitantly with streptozotocin. However, it is still puzzling the fact that only mDNA from diabetic mice activates the NLRP3 inflammasome.

Besides homeostasis-altering compounds, exogenous molecules can also alter the macrophage status of activation (25). Crystalline silica reduces the activation of macrophages by reducing TLR2 expression (Beamer et al.). Previous studies established that the scavenger receptor CD204 is important for the binding/ uptake of silica $(26,27)$. It has been also demonstrated that silica crystals activate NLRP3 inflammasome and induce IL1 $\beta$ production (28), a mechanism dependent of the first signal triggered by the TLR4 agonist, LPS. Beamer et al. demonstrated, on the other hand, that silica crystals leads to less IL1 $\beta$ production after Pam3CSK4 and Pam2CSK4 stimulus, lipopeptides recognized by the TLR $2 / 1$ and TLR $2 / 6$ heterodimer, respectively (Beamer et al.). Tissue-resident intestinal macrophages can also contribute to the gut homeostasis by eliminating invading pathogens without inducing a robust inflammatory response (Kühl et al.). Bone marrow-derived monocytes are the precursor cells of tissue-resident intestinal macrophages (29) and in the context of ulcerative colitis (UC) and Crohn's diseases (CD), increased numbers of M1 macrophages are observed despite monocyte infiltration. In addition, lesions of UC, but not CD, are characterized by impaired bacterial clearance, formation of granulomas, inflamed mesenteric fat tissue, and pronounced fibrosis.

The prevention of damage that would be caused by macrophage prolonged activation is achieved by changes in their transcriptional program (Hamidzadeh and Mosser). ATP and adenosine can diminish the production of inflammatory cytokines by macrophages (30). In an inflammatory scenario, TLR-stimulated macrophages undergo metabolic alterations that result in an increase rate of aerobic glycolysis and production of ATP. This nucleotide is rapidly hydrolyzed to adenosine on the macrophage surface by CD39 and CD73 (30). Following TLR stimulation, macrophages dramatically upregulate their expression of receptors for adenosine, in a physiological self-regulating program. In addition, it has been demonstrated that IFN $\gamma$ sustains macrophage inflammatory responses, by attenuating their sensitivity to extracellular adenosine (31). This decreased macrophage sensitivity to adenosine delays the transition of macrophages to a regulatory phenotype, allowing them to sustain macrophage activation for the duration of an adaptive immune response. IFN $\gamma$-mediated adenosine sensitivity signals through STAT1 (31); however, the exact mechanism whereby IFN $\gamma$ affects the macrophage activation remain to be enlightened. However, when not controlled, blood-borne infections change the splenic microenvironment and can ultimately lead to splenomegaly (32). Splenic architecture and differences among red pulp (RpM $\Phi$ s), marginal metallophilic (MMMФs), and marginal zone macrophages (MZMФs) were described by Borges da Silva et al. CD47, a self-molecule ubiquitously expressed on many cell types, function as an inhibitory signal for phagocytosis (33) and red blood cells expressing a modified isoform of CD47 are phagocytized by RpMФs (34). MZMФs and MMMФs populate the interface between the bloodstream and lymphocyte-rich zones, and for this reason they are candidate cells to bridge innate and adaptive immunity. In this collection of articles, the authors show how macrophages influence chronic inflammatory diseases, and how the understanding of their biology can contribute to improved scenario for balance the homeostasis. We hope this collection can help further studies on the development of new therapies and in the better understanding of the biology of these cells.

\section{AUTHOR CONTRIBUTIONS}

TB wrote the manuscript. IM, AL, and NC helped to evaluate and edit the manuscript. 


\section{REFERENCES}

1. Wynn TA, Ramalingam TR. Mechanisms of fibrosis: therapeutic translation for fibrotic disease. Nat Med (2012) 18(7):1028-40. doi:10.1038/nm.2807

2. Cao Q, Wang Y, Harris DC. Macrophage heterogeneity, phenotypes, and roles in renal fibrosis. Kidney Int Suppl (2014) 4(1):16-9. doi:10.1038/kisup.2014.4

3. Conway B, Hughes J. Cellular orchestrators of renal fibrosis. QJM (2012) 105(7):611-5. doi:10.1093/qjmed/hcr235

4. Selman M, Pardo A. Role of epithelial cells in idiopathic pulmonary fibrosis: from innocent targets to serial killers. Proc Am Thorac Soc (2006) 3(4):364-72. doi:10.1513/pats.200601-003TK

5. Li D, Guabiraba R, Besnard AG, Komai-Koma M, Jabir MS, Zhang L, et al. IL-33 promotes ST2-dependent lung fibrosis by the induction of alternatively activated macrophages and innate lymphoid cells in mice. J Allergy Clin Immunol (2014) 134(6):1422-32.e11. doi:10.1016/j.jaci.2014.05.011

6. Doucet C, Brouty-Boyé D, Pottin-Clémenceau C, Canonica GW, Jasmin C, Azzarone B. Interleukin (IL) 4 and IL-13 act on human lung fibroblasts. Implication in asthma. J Clin Invest (1998) 101(10):2129-39. doi:10.1172/ JCI741

7. Halim TY, Steer CA, Mathä L, Gold MJ, Martinez-Gonzalez I, McNagny KM, et al. Group 2 innate lymphoid cells are critical for the initiation of adaptive $\mathrm{T}$ helper 2 cell-mediated allergic lung inflammation. Immunity (2014) 40(3):425-35. doi:10.1016/j.immuni.2014.01.011

8. Oliphant CJ, Hwang YY, Walker JA, Salimi M, Wong SH, Brewer JM, et al. MHCII-mediated dialog between group 2 innate lymphoid cells and CD4(+) T cells potentiates type 2 immunity and promotes parasitic helminth expulsion. Immunity (2014) 41(2):283-95. doi:10.1016/j.immuni.2014.06.016

9. Hams E, Armstrong ME, Barlow JL, Saunders SP, Schwartz C, Cooke G, et al. IL-25 and type 2 innate lymphoid cells induce pulmonary fibrosis. Proc Natl Acad Sci U S A (2014) 111(1):367-72. doi:10.1073/pnas.1315854111

10. McHedlidze T, Waldner M, Zopf S, Walker J, Rankin AL, Schuchmann M, et al. Interleukin-33-dependent innate lymphoid cells mediate hepatic fibrosis. Immunity (2013) 39(2):357-71. doi:10.1016/j.immuni.2013.07.018

11. Fallon PG, Ballantyne SJ, Mangan NE, Barlow JL, Dasvarma A, Hewett DR, et al. Identification of an interleukin (IL)-25-dependent cell population that provides IL-4, IL-5, and IL-13 at the onset of helminth expulsion. J Exp Med (2006) 203(4):1105-16. doi:10.1084/jem.20051615

12. Lumeng CN, DelProposto JB, Westcott DJ, Saltiel AR. Phenotypic switching of adipose tissue macrophages with obesity is generated by spatiotemporal differences in macrophage subtypes. Diabetes (2008) 57(12):3239-46. doi:10.2337/ db08-0872

13. Xu X, Grijalva A, Skowronski A, van Eijk M, Serlie MJ, Ferrante AW. Obesity activates a program of lysosomal-dependent lipid metabolism in adipose tissue macrophages independently of classic activation. Cell Metab (2013) 18(6):816-30. doi:10.1016/j.cmet.2013.11.001

14. Kratz M, Coats BR, Hisert KB, Hagman D, Mutskov V, Peris E, et al. Metabolic dysfunction drives a mechanistically distinct proinflammatory phenotype in adipose tissue macrophages. Cell Metab (2014) 20(4):614-25. doi:10.1016/j. cmet.2014.08.010

15. Gao Z, Hwang D, Bataille F, Lefevre M, York D, Quon MJ, et al. Serine phosphorylation of insulin receptor substrate 1 by inhibitor kappa B kinase complex. J Biol Chem (2002) 277(50):48115-21. doi:10.1074/jbc.M209459200

16. Hirosumi J, Tuncman G, Chang L, Görgün CZ, Uysal KT, Maeda K, et al. A central role for JNK in obesity and insulin resistance. Nature (2002) 420(6913):333-6. doi:10.1038/nature01137

17. Laplante M, Sabatini DM. mTOR signaling in growth control and disease. Cell (2012) 149(2):274-93. doi:10.1016/j.cell.2012.03.017

18. Chawla A, Nguyen KD, Goh YP. Macrophage-mediated inflammation in metabolic disease. Nat Rev Immunol (2011) 11(11):738-49. doi:10.1038/nri3071

19. Harms M, Seale P. Brown and beige fat: development, function and therapeutic potential. Nat Med (2013) 19(10):1252-63. doi:10.1038/nm.3361
20. Kir S, Spiegelman BM. Cachexia \& brown fat: a burning issue in cancer. Trends Cancer (2016) 2(9):461-3. doi:10.1016/j.trecan.2016.07.005

21. Phan AT, Goldrath AW, Glass CK. Metabolic and epigenetic coordination of $\mathrm{T}$ cell and macrophage immunity. Immunity (2017) 46(5):714-29. doi:10.1016/j.immuni.2017.04.016

22. Filgueiras LR, Brandt SL, Wang S, Wang Z, Morris DL, Evans-Molina C, et al. Leukotriene B4-mediated sterile inflammation promotes susceptibility to sepsis in a mouse model of type 1 diabetes. Sci Signal (2015) 8(361):ra10. doi:10.1126/scisignal.2005568

23. Hu C, Ding H, Li Y, Pearson JA, Zhang X, Flavell RA, et al. NLRP3 deficiency protects from type 1 diabetes through the regulation of chemotaxis into the pancreatic islets. Proc Natl Acad Sci U S A (2015) 112(36):11318-23. doi:10.1073/pnas.1513509112

24. Pontillo A, Brandao L, Guimaraes R, Segat L, Araujo J, Crovella S. Two SNPs in NLRP3 gene are involved in the predisposition to type-1 diabetes and celiac disease in a pediatric population from northeast Brazil. Autoimmunity (2010) 43(8):583-9. doi:10.3109/08916930903540432

25. Liston A, Masters SL. Homeostasis-altering molecular processes as mechanisms of inflammasome activation. Nat Rev Immunol (2017) 17(3):208-14. doi:10.1038/nri.2016.151

26. Thakur SA, Beamer CA, Migliaccio CT, Holian A. Critical role of MARCO in crystalline silica-induced pulmonary inflammation. Toxicol Sci (2009) 108(2):462-71. doi:10.1093/toxsci/kfp011

27. Beamer CA, Holian A. Scavenger receptor class A type I/II (CD204) null mice fail to develop fibrosis following silica exposure. Am J Physiol Lung Cell Mol Physiol (2005) 289(2):L186-95. doi:10.1152/ajplung.00474.2004

28. Hornung V, Bauernfeind F, Halle A, Samstad EO, Kono H, Rock KL, et al. Silica crystals and aluminum salts activate the NALP3 inflammasome through phagosomal destabilization. Nat Immunol (2008) 9(8):847-56. doi:10.1038/ ni. 1631

29. Smythies LE, Maheshwari A, Clements R, Eckhoff D, Novak L, Vu HL, et al. Mucosal IL-8 and TGF-beta recruit blood monocytes: evidence for cross-talk between the lamina propria stroma and myeloid cells. J Leukoc Biol (2006) 80(3):492-9. doi:10.1189/jlb.1005566

30. Cohen HB, Briggs KT, Marino JP, Ravid K, Robson SC, Mosser DM. TLR stimulation initiates a CD39-based autoregulatory mechanism that limits macrophage inflammatory responses. Blood (2013) 122(11):1935-45. doi:10.1182/blood-2013-04-496216

31. Cohen HB, Ward A, Hamidzadeh K, Ravid K, Mosser DM. IFN- $\gamma$ prevents adenosine receptor (A2bR) upregulation to sustain the macrophage activation response. J Immunol (2015) 195(8):3828-37. doi:10.4049/jimmunol.1501139

32. Mebius RE, Kraal G. Structure and function of the spleen. Nat Rev Immunol (2005) 5(8):606-16. doi:10.1038/nri1669

33. Olsson M, Oldenborg PA. CD47 on experimentally senescent murine RBCs inhibits phagocytosis following Fcgamma receptor-mediated but not scavenger receptor-mediated recognition by macrophages. Blood (2008) 112(10):4259-67. doi:10.1182/blood-2008-03-143008

34. Burger P, Hilarius-Stokman P, de Korte D, van den Berg TK, van Bruggen R. CD47 functions as a molecular switch for erythrocyte phagocytosis. Blood (2012) 119(23):5512-21. doi:10.1182/blood-2011-10-386805

Conflict of Interest Statement: The authors declare that the research was conducted in the absence of any commercial or financial relationships that could be construed as a potential conflict of interest.

Copyright (c) 2017 Braga, Moura, Lepique and Camara. This is an open-access article distributed under the terms of the Creative Commons Attribution License (CC BY). The use, distribution or reproduction in other forums is permitted, provided the original author(s) or licensor are credited and that the original publication in this journal is cited, in accordance with accepted academic practice. No use, distribution or reproduction is permitted which does not comply with these terms. 